Original Research Article

\title{
Knowledge, attitude and practices of rural medical practitioners on generic medicines
}

\author{
Susmitha Vemu, Triveni Manchu*, Meenakshi Lella
}

Department of Pharmacology, Guntur Medical College, Guntur, Andhra Pradesh, India

Received: 06 May 2019

Accepted: 05 June 2019

\section{*Correspondence to: \\ Dr. Triveni Manchu, \\ Email: triveni.manchu \\ @gmail.com}

Copyright: (C) the author(s), publisher and licensee Medip Academy. This is an openaccess article distributed under the terms of the Creative Commons Attribution NonCommercial License, which permits unrestricted noncommercial use, distribution, and reproduction in any medium, provided the original work is properly cited.

\begin{abstract}
Background: An unqualified medical practitioner without any formal registration and practicing allopathic medicine in rural areas in India can be called Rural Medical Practitioner (RMP). RMPs enjoy a great deal of practice in rural areas by taking advantage of lacunae in the public health system. Government of India is currently popularising generic medicines, but still certain doubts exist even among doctors and how far the RMPs are aware of generic medicines is a big issue. They influence a lot of uneducated people, so the knowledge, attitude and practices they follow have a large impact on society.

Methods: A cross sectional, prospective study was undertaken to assess the knowledge, attitude and the practices of 152 RMPs on generic medicines for a period of three months. A 23-item questionnaire was well designed, pre-validated and distributed to RMPs in and around Guntur district. The results were analysed using descriptive statistics.

Results: $92 \%$ of the participants were aware of generic drugs. More than $80 \%$ believed that they are equivalent in terms of efficacy and safety to their branded counterparts and are available at reasonable prices. 95.4\% RMPs believed that prescribing generic drugs will decrease the pharmaco-economic burden of the country. Almost all of them agreed on the need for the updates and education on generics by means of continuing medical education (CMEs).

Conclusions: The participants had good amount of knowledge on generic drugs but there are concerns regarding quality and therapeutic efficacy of generic drugs. Proper awareness about the generic prescription practice may improve the patient compliance by reducing economic burden to the patients.
\end{abstract}

Keywords: Attitude, Generics, Knowledge, Practice, RMP

\section{INTRODUCTION}

Rising health care expenses is of major concern in health care system. Medicines constitute a major share in these expenses. In order to reduce these expenses, generic drugs are a good substitute. The generic drug is defined as a medication that is produced freely after expiry of the patent protecting the branded product, necessarily being similar to the reference drug in bioequivalence in order to obtain the same therapeutic effect. ${ }^{1}$ Since generic drug manufacturers do not have to spend extra money for drug discovery, pre-clinical and clinical trials, generics are generally cheaper than brands. Since generics are availableat a lower cost, they provide an opportunity for savings in drug expenditure without reducing the quality. ${ }^{2}$ India is well known for its prolific medicine industry and offers low cost quality generic medicines to more than two hundred countries in the world. At home, however, India faces the challenge of equal access to affordable and quality essential medicines for its own population.The Pradhan Mantri Bharatiya Jan Aushadi Kendra (PMBJK) was launched by the Department of Pharmaceuticals, 
Government of India with the aim of providing generic medicines at affordable costs to the masses through their special kendras known as Pradhan Mantri Bhartiya Jan Aoushadi Kendra. The main focus and aim of this scheme is to make these medicines available at most affordable prices, through the exclusive outlets - "Jan Aushadi Medical Store". Till 2018 there are over 3200 Jan Aushadhi drug stores across the country. Jan Aushadhi centers in the country provide generic medicines of 230 different kinds of drug formulations. ${ }^{3}$

The Red Cross and a few other non-government organisations run these drug stores. In Government General Hospital, Guntur a Jan Aoushadi generic outlet was established to encourage generic drug use. Pradhan Mantri Jan Drugs Campaign was basically started to make the public aware and understand that generic medicines are available at lower prices compared to branded medicine and there is no dearth of quality in it. On the website www.pmyojana.online the locations of stores as per PM Jan Aushadhi Yojana can be detected very easily.

"Quality use of generic medicines" can be promoted with a better understanding of views, knowledge and perception. Inaccurate or insufficient knowledge of healthcare providers about generics causes hesitation on the use of these drugs and especially about their efficacies and this is becoming a major barrier to a wider use of these products. ${ }^{4,5}$ Existing negative perceptions surrounding the quality of generic medicines must be addressed to ensure that people use them with confidence. ${ }^{6}$

Branded medicines are strongly promoted, and these promotional costs also add to their Maximum Retail Prices (MRP). ${ }^{7}$ Generic drugs should be promoted in social and print media so that people become aware of these drugs and use them without any fear. Most of the prescriptions have branded medicines written on them, although prescription guidelines promote generic prescriptions. ${ }^{8}$ It is mandatory that all the health care professionals and also rural healthcare practitioners should be made aware of the importance of generic drugs. India is a developing country with lot of people living in rural areas who have immediate and easy access to RMPs in case of any medical ailments. The official definition of an RMP is a village doctor who practices allopathic medicines without proper registration/approval or any legal sanction. ${ }^{9}$

It is questionable as to how much these RMPs know about the diseases and the drugs that are prescribed. This group of self-styled practitioners, despite their lack of knowledge hold a good position in rural areas because lay people confuse them to doctors. It is only prudent that RMPs should be aware of generic and branded drugs and what holds good for the people in rural areas. Previously not many studies were conducted on these rural practitioners regarding awareness of generic medicines. Hence this study was done to assess the extent of knowledge, attitude and practices among rural medical practitioners.

\section{METHODS}

A cross sectional questionnaire-based study was conducted on RMPs in and around Guntur district for a period of 3 months (November 2018 to January 2019) after prior approval from the Institutional Ethics Committee, GGH, Guntur and after obtaining proper informed consent. A well designed, pre-validated 23 item questionnaire was distributed to 180 RMPs out of which 152 of them responded. Out of 152, 126 were male participants and 26 were female participants. The RMPs were personally visited and questionnaires were distributed in their local language. The answered questionnaires were collected after 1 week of distribution. The questionnaire included questions to assess the knowledge, attitude and practices of the RMPs regarding the generic drugs. The questionnaire was well structured and closed ended with answers as yes/no. It comprised of four sections, demographic data, eight questions regarding knowledge, five questions eliciting attitude and seven questions relating to practice. With regard to generic medications, knowledge was assessed towards awareness, cost, quality, availability of generic stores, attitudes were assessed regarding the education by means of conducting CMEs, influence of advertisements and incentives, personal and family use and prescribing practices and preferences among RMPs. The data was analysed using SPSS 16.0 version and data was expressed in frequency and percentages wherever necessary.

\section{RESULTS}

A total of 152 RMPs participated in the present study and answered the given questionnaire. Majority of them were male $(82.9 \%)$. The mean age of was $40.09 \pm 9.3$ years. Most of them had a minimum educational qualification of Board of Intermediate Examination, Bachelor of Science (B.Sc) and Secondary School Certificate Examination (SSC). The mean years of practice of the participants was $9.7 \pm 7.7$ years. Demographic details of the participants were summarized in Table 1.

\section{Knowledge of RMPs regarding generics}

In the present study, almost all the participants $(92.1 \%)$ were aware of generics. $88.8 \%$ of them were also aware that these drugs were not low grade or duplicate and that they have same active content and in equal amounts as their branded counterparts. Majority of the participants had an understanding that generic medicines have same efficacy $(88.8 \%)$ as branded drugs and that they do not have more side effects $(89.4 \%)$ compared to branded drugs. $88.8 \%$ of them were conscious of the availability of generic stores like Sanjeevani and Jan Aoushadi in their locality and $86.9 \%$ of them agree that these were not costly and available at affordable prices. Only $55.3 \%$ of the participants were knowledgeable on the laws enforced by the Government of India regarding the use of generic drugs. Knowledge related questionnaire and responses were summarized in Table 2. 
Table 1: Demographic details of the study participants.

\begin{tabular}{|llll|}
\hline Parameter & & Frequency & Percentage (\%) \\
\hline Gender & Male & 126 & 82.9 \\
\hline Education & Female & 26 & 17.1 \\
\hline & SSC & 41 & 27 \\
\hline & Intermediate & 51 & 33.6 \\
\hline & DMLT & 2 & 1.3 \\
\hline & GNM & 1 & 0.7 \\
\hline & B.Sc & 48 & 31.5 \\
\hline Age (years) & D.Pharm & 9 & 5.9 \\
\hline & $21-30$ & 29 & 19 \\
\hline & $31-40$ & 65 & 42.6 \\
\hline & $41-50$ & 37 & 24.4 \\
\hline & $>50$ & 21 & 14 \\
\hline Years of practice (years) & Mean age & $40.09 \pm 9.3$ years & \\
\hline & $0-5$ & 45 & 29.6 \\
\hline & $6-10$ & 74 & 48.8 \\
\hline & $11-15$ & 11 & 7.2 \\
\hline & $16-20$ & 7 & 4.6 \\
\hline & $>20$ & 15 & 9.8 \\
\hline
\end{tabular}

DMLT-Diploma in Medical Laboratory Technology, GNM- General Nursing and Midwifery, D. Pharma-Diploma in Pharmacy

Table 2: Knowledge based questions and frequency of responses.

\begin{tabular}{|lll|}
\hline Question & \multicolumn{2}{l|}{ Frequency (\%) } \\
\hline Aware of generic medicines & Yes & No \\
\hline Generic drugs are low grade and duplicate medicines & $140(92.1)$ & $12(7.9)$ \\
\hline $\begin{array}{l}\text { Generic medicines have same active contents and in equal amounts to its branded } \\
\text { counterparts }\end{array}$ & $17(11.2)$ & $135(88.8)$ \\
\hline Generic medicines have same efficacy as its branded counterparts & $140(92.1)$ & $12(7.9)$ \\
\hline Generics produce more side effects & $135(88.8)$ & $17(11.2)$ \\
\hline Generic drugs are costly & $16(10.6)$ & $136(89.4)$ \\
\hline Knowledge on the availability of generic stores (Sanjeevani, Jan Aoushadi) in your locality & $20(13.1)$ & $132(86.9)$ \\
\hline Laws passed by the government of India regarding the use of generic medicines & $84(55.8)$ & $17(11.2)$ \\
\hline
\end{tabular}

\section{Attitude of RMPs on generics}

92.1\% of the RMPs think that advertisements by the branded companies do not influence their prescription. Over $95.3 \%$ of them were of the viewpoint that enough information regarding generic drugs should be given to the patients. Majority believed that prescribing generics would decrease Pharmaco-economic burden (95.4\%) of the country.

Almost $82.3 \%$ of them believe that the Government of India should give tax benefits to the generic drug manufacturers. All of them have a positive outlook on educating and updating the practising RMPs on generic drugs via CMEs and workshops. Attitude related questionnaire and responses were listed out in Table 3

\section{Practice related questions and responses}

Over $85.5 \%$ of the participants think prescribing a drug by its generic name should be made mandatory. $87.5 \%$ of them prefer generics for personal or family use.

More than $82.3 \%$ of them revealed that the patients neither complained of the cost of the drugs nor requested for any branded or generic drug specifically but $84.9 \%$ of the agreed that their prescription is influenced by the income status of the patients. $88.2 \%$ of the participants said that they were not influenced by the incentives given by the pharmaceutical companies. Almost all of them (95.3\%) suggested that media advertising and publicity should be increased for generic drugs. Details of practice related responses were shown in Table 4. 
Table 3: Attitude related questions and responses.

\begin{tabular}{|lll|}
\hline Question & Frequency (\%) \\
\hline Enough information should be given to patients on generic medicines & Yes & No \\
\hline Advertisement by branded drug companies influence the prescription & $145(95.3)$ & $7(4.7)$ \\
\hline Prescribing generics will decrease Pharmaco-economic burden of the country & $12(7.9)$ & $140(92.1)$ \\
\hline Government should give tax benefits for the generic drug manufacturers & $145(95.4)$ & $7(4.7)$ \\
\hline Practising RMPs should be educated on generic drugs by means of CME & $125(82.3)$ & $27(17.7)$ \\
\hline
\end{tabular}

Table 4: Practice related questions and responses.

\begin{tabular}{|lll|}
\hline \multirow{2}{*}{ Question } & \multicolumn{3}{l|}{ Frequency $(\%)$} \\
\hline Prescribing a drug by generic name should be made mandatory & Yes & No \\
\hline Prefer generics for personal/family use & $130(85.5)$ & $22(14.5)$ \\
\hline Patients complain of drug cost & $133(87.5)$ & $19(12.5)$ \\
\hline Patients insist on prescribing a generic drug & $27(17.7)$ & $125(82.3)$ \\
\hline Prescription influenced by patient's income status & $32(21.1)$ & $120(78.9)$ \\
\hline Prescription influenced by incentives given by branded Companies & $129(84.9)$ & $23(15.1)$ \\
\hline Suggest media advertising and publicity on generic drugs & $18(11.8)$ & $134(88.2)$ \\
\hline
\end{tabular}

\section{DISCUSSION}

The main objective of this study was to assess the awareness, attitude and practices of RMPs as generic substitution is considered as a major cost minimizing strategy meant to curtail pharmaceutical expenditure without compromising health care quality.

This study included RMPs who practice in the nearby villages with an average experience of $9.7 \pm 7.7$ years and with a minimum qualification of SSC, Intermediate and B.Sc. In the present study it was clearly evident that these practicing RMPs were well aware of generic drugs, which coincides with similar studies done by Desai $\mathrm{S}$ et al, on Physicians (87\%) and by Ahire $\mathrm{k}$ et al, on population of non-science background (75\%). ${ }^{10,11}$ This is in contrast to the study done by Hebbar SK et al, which stated that only $5 \%$ of laypersons were aware. ${ }^{1}$ Majority of the participants were aware that generic drugs have same active content as their branded counterparts in consistence with the study done by Gupta SK et al, on doctors (76.7\%). ${ }^{12}$ Most of them agree that these drugs are not inferior or duplicate, are of same efficacy with no more side effects and are available at affordable prices compared to their branded counterparts. These results were comparable to the studies done by Gupta $\mathrm{R}$ et al, on doctors and Ahire $\mathrm{K}$ et al on population with non-science background. ${ }^{11,13}$ In the present study $88.8 \%$ of them were aware of the availability of the generic stores in their locality in contrast to a study done by Desai $\mathrm{S}$ et al, on doctors and post graduates. Hence the participants are more aware of PMBJK scheme..$^{10}$ Only $55 \%$ of them were aware of the laws governing the usage of generic drugs in contrast to the studies by Gupta $\mathrm{R}$ et al, and Badwai RT et al, where $80 \%$ and $68 \%$ of physicians were aware of it respectively. 13,14

Low cost of generics is a major boon to the community which cuts down the healthcare related costs. In the present study, $95.4 \%$ agreed that prescribing generics will decrease the pharmaco-economic burden. These results are consistent with studies done by Gupta R, et al, and Desai S et al, where $88 \%$ and $80 \%$ of participants agreed to it respectively. ${ }^{10,13} 92.1 \%$ of the RMPs disclosed that their prescription is not influenced by advertisements of branded companies which is consistent with a study done by Khadke VV et al. ${ }^{7}$ Majority (82.3\%) of the participants agreed that tax benefits should be given to generic drug manufacturers similar to the study done by Desai $\mathrm{S}$ et al, where $80 \%$ of physicians agreed to the statement. ${ }^{10}$ In the present study all the practising RMPs opined that they should be educated on generic drugs by means of CMEs. These results are comparable to studies done by Gupta SK et al, and Gupta $\mathrm{R}$ et al. ${ }^{12,13}$ This emphasises the role of educational programmes in strengthening the implementation of generic prescribing.

$84.9 \%$ of the participants agreed that their prescription is influenced by patient's income status which was similar to the studies done by Khadke VV et al and Desai S et al. ${ }^{7,10}$ Only $11.8 \%$ of the RMPs agreed that their prescription is influenced by incentives given by branded Companies similar to a study done by Khadke VV et al, where only $3 \%$ agreed to it. $787.5 \%$ of the participants preferred generics for personal/family use in contrast to a study by Khadke VV et al, where only $57 \%$ preferred. $^{7}$ 95.3\% of the participants suggested media advertising and publicity on generic drugs similar to studies done by Desai $\mathrm{S}$ et al, and Sadiq $\mathrm{S}$ et al. ${ }^{3,10}$ 


\section{CONCLUSION}

The present study shows that the participants had good amount of knowledge on generic drugs, but this was not reflected in regular practice because of the concerns regarding quality and therapeutic efficacy of these drugs. These concerns can be alleviated by creating awareness for RMPs by conducting regular workshops and CMEs. There is also an immediate need to carryout comparative quality evaluation studies on generics to instill confidence among the patients as well as healthcare providers. Availability of Jan Aoushadi stores should be more popularised via media to the public so that they can afford quality medicines at reasonable prices. Policy to check the influence on health care providers by pharmaceutical industries through incentives needs to be formulated and implemented. There should be strict implementation of rules and laws passed by the Government of India regarding the usage of generic drugs. Providing detailed information about the generics is of utmost importance to promote prescription of these drugs.

\section{ACKNOWLEDGEMENTS}

Authors would like to thank the RMPs in and around Guntur district for actively participating and answering the entire questionnaire given to them. Authors are grateful to the Department of Pharmacology, Guntur Medical College, Guntur, Andhra Pradesh, India for guiding us throughout.

\section{Funding: No funding sources}

Conflict of interest: None declared

Ethical approval: The study was approved by the Institutional Ethics Committee

\section{REFERENCES}

1. Hebbar SK, Nalini GK, Deepak P, Sahana GN, Nagaral JV. Assessment of awareness on generic drugs among health care professionals and laypersons. Int J Basic Clin Pharmacol. 2017;6:680-3.

2. Joshi SS, Shetty YC, Karande S. Generic drugs-The Indian scenario. J Postgrad Med. 2019;65(2):67-9.

3. Sadiq S, Khajuria V, Khajuria K. Knowledge, attitude, and practices towards Jan Aushadhi scheme. Natl J Physiol Pharm Pharmacol. 2017;7(9):977-82.

4. Basak SC, Sathyanarayana D. Exploring knowledge and perceptions of generic medicines among drug retailers and community pharmacists. Indian J Pharm Sci. 2012;74(6):571-5.

5. Auta A, Bala ET, Shalkur D. Generic medicine substitution: a cross-sectional survey of the perception of pharmacists in North Central, Nigeria. Med Princ Pract. 2014;23(1):53-8.

6. Costa Font J, Rudisill C, Tan S. Brand loyalty, patients and limited generic medicines uptake. Health Policy. 2014;116(2-3):224-33.

7. Khadke VV, Khanda SY. To study doctor's beliefs, barriers, awareness, and actual practices regarding use of generic medicines. Int $\mathrm{J}$ Basic Clin Pharmacol. 2017;6:1871-9.

8. Guide to good prescribing- a practical manual. World Health Organisation, action programme on Essential drugs, Geneva. WHO/DAP/94.11. Available at: https://apps.who.int/medicinedocs/pdf/whozip23e/wh ozip23e.pdf.

9. Rao UP, Rao NSS. The rural medical practitioner of India. J Evolution Med Dent Sci. 2017;6(74):5321-3.

10. Desai S, Dass AP, Kaniganti S. Assessment of perception and attitude of postgraduates and clinicians toward generic versus branded medicines at a teaching medical institute. Natl J Physiol Pharm Pharmacol. 2018;8(4):540-3.

11. Ahire K, Shukla M, Gattani M, Singh V, Singh MA. survey based study in current scenario of generic and branded medicines. Int J Pharm Sci. 2013;5(3):705-11.

12. Gupta SK, Nayak RP, Vidyarthi SK. A study on the knowledge, attitude, and practice of generic medicines among the doctors in a tertiary care teaching hospital in South India. Natl J Phys Pharm Pharm. 2015;5(1):39-44.

13. Gupta R, Malhotra A, Malhotra P. A study on assessment of awareness on generic drugs among doctors in a tertiary care teaching hospital in northIndia. Int J Res Med Sci. 2018; 6(4):1362-7.

14. Badwaik RT, Chopade SS, Mahajan HM, Honrao R. Prescribers Views on Generic Medicines: A study on knowledge, attitude and practice J Cont Med A Dent. 2015;3(2):27-32.

Cite this article as: Vemu S, Manchu T, Lella M. Knowledge, attitude and practices of rural medical practitioners on generic medicines. Int $\mathrm{J}$ Basic Clin Pharmacol 2019;8:1652-6. 